\title{
Field testing of polymeric mesh and ash-based ceramic membranes in a membrane bioreactor (MBR) for decentralised sewage treatment
}

\author{
PK Tewari, RK Singh, VS Batra and M Balakrishnan* \\ The Energy and Resources Institute (TERI), Darbari Seth Block, India Habitat Centre, Lodhi Road, New Delhi 110003, India
}

\begin{abstract}
This paper presents the initial findings of field testing of 2 low-cost membrane filters, viz. $30 \mu \mathrm{m}$ polymeric mesh and 2-6 $\mu \mathrm{m}$ macroporous waste-ash based ceramic filter, in a submerged membrane bioreactor (MBR) employing batch anoxic and aerobic conditions. The influent was raw wastewater from a residential complex located near Delhi, India. The results indicated that the ceramic filter was able to operate for longer periods without cleaning; however, there is a limit to the transmembrane pressure it can withstand. The suspended solids retention was high with both filters (average of $96 \%$ ). Moderate reduction in chemical oxygen demand (COD), total nitrogen $\left(\mathrm{NH}_{4}^{+}\right)$and total phosphorus $\left(\mathrm{PO}_{4}^{3-}\right)$ was achieved. The improvements in operation required in such systems are also underlined.
\end{abstract}

Keywords: membrane separation; activated sludge, sewage treatment; polymeric mesh; fly ash ceramic membrane

\section{Introduction}

Sewage treatment poses a major challenge in expanding urban areas in India. Due to fast and unplanned growth combined with multiple and dispersed wastewater outlets, centralised treatment plants have limited effectiveness. Further, the shift towards wastewater reclamation and reuse as well as more stringent discharge standards is encouraging the adoption of decentralised systems. Membrane bioreactors (MBRs) are an attractive option because of their modular construction, small footprint and high treated-effluent quality. Further, they offer the opportunity for technology leapfrogging where sewage coverage is limited or non-existent. As the membrane itself constitutes a significant fraction of the total capital cost, there is an interest in exploring low-cost alternatives. This includes woven fabric and mesh (e.g., Kiso et al., 2000; Chang et al., 2001, 2007; Wu et al., 2005) as well as ceramic membranes prepared from naturally occurring or waste materials (e.g. Nandi et al., 2009; Jedidi et al., 2009). The concept of employing low-cost membranes made from waste material in decentralised systems is a step towards sustainability and is therefore of importance in developing countries.

In our earlier work in a submerged aerobic MBR fed with synthetic wastewater (Tewari et al., 2010), we compared the filtration performance of 2 low-cost filters, viz. a $30 \mu \mathrm{m}$ commercial polymeric mesh and a $2-6 \mu \mathrm{m}$ macroporous ceramic membrane filter developed in-house. Both the filters were good solid-liquid separators with low transmembrane pressure (TMP) build-up but the performance of the ceramic filter was noticeably better. This paper presents the initial results from the field-testing of these filters with domestic sewage and highlights the improvements, including optimisation of the operation procedure, which is required in such systems.

\footnotetext{
* To whom all correspondence should be addressed.

용 +91-11-2468 2100; fax: +91-11-2468 2144; e-mail: malinib@teri.res.in

Received 27 April 2011; accepted in revised form 20 September 2012
}

\section{Experimental}

\section{Experimental setup}

The MBR pilot was established in a residential training complex on the outskirts of Delhi in Gual Pahari, Haryana. The occupancy of this complex varied from 15 to 150 persons at any given time.

Two filter modules constructed with polymeric mesh (30 $\mu \mathrm{m}$ nylon and filtration area of $\left.0.075 \mathrm{~m}^{2}\right)$ and ceramic filter $(2$ to $6 \mu \mathrm{m}$ fly-ash based and filtration area of $0.07 \mathrm{~m}^{2}$ ) were tested in parallel. The ceramic filter was prepared in-house (Batra and Tewari, 2006) while the polymeric mesh was obtained commercially (Trace Scientific Corporation, India). For each module, a pressure gauge (Jaspin Industrial Instrumentation, Delhi, India) mounted in the permeate line measured the transmembrane pressure (TMP). An air diffuser with $1 \mathrm{~mm}$ slit length (Southern Cogen Systems Pty. Ltd., Chennai, India) was located under each filter module. Compressed air in the range of $12.5-16.5 \ell \cdot \mathrm{min}^{-1}$ was supplied. Aeration rate was measured using a rotameter (Jaspin Industrial Instrumentation, Delhi, India). The influent was screened with a $0.5 \mathrm{~mm}$ sieve to remove large suspended particles. Table 1 summarises the average properties of the influent. The screened influent was fed to the reactor at a controlled rate that was synchronised with the permeate withdrawal. Peristaltic pumps (Enertech ENDP-100 Optima, Pragati Biomedical, Mumbai, India) were used for both influent feeding and permeate removal.

\begin{tabular}{|l|l|}
\hline \multicolumn{2}{|c|}{$\begin{array}{c}\text { Table 1 } \\
\text { Influent wastewater properties }\end{array}$} \\
\hline Parameters & Value (Average \pm std. dev.) \\
\hline $\mathrm{pH}$ & $7.08 \pm 0.39$ \\
\hline $\mathrm{COD}\left(\mathrm{mg} \cdot \ell^{-1}\right)$ & $249.31 \pm 136.66$ \\
\hline $\mathrm{MLSS}\left(\mathrm{g} \cdot \ell^{-}\right)$ & $0.49 \pm 0.34$ \\
\hline $\mathrm{NH}_{4}-\mathrm{N}\left(\mathrm{mg} \cdot \ell^{-}\right)$ & $1.36 \pm 0.79$ \\
\hline $\mathrm{PO}_{4}-\mathrm{P}\left(\mathrm{mg} \cdot \ell^{-}\right)$ & $14.84 \pm 8.17$ \\
\hline
\end{tabular}


(a)
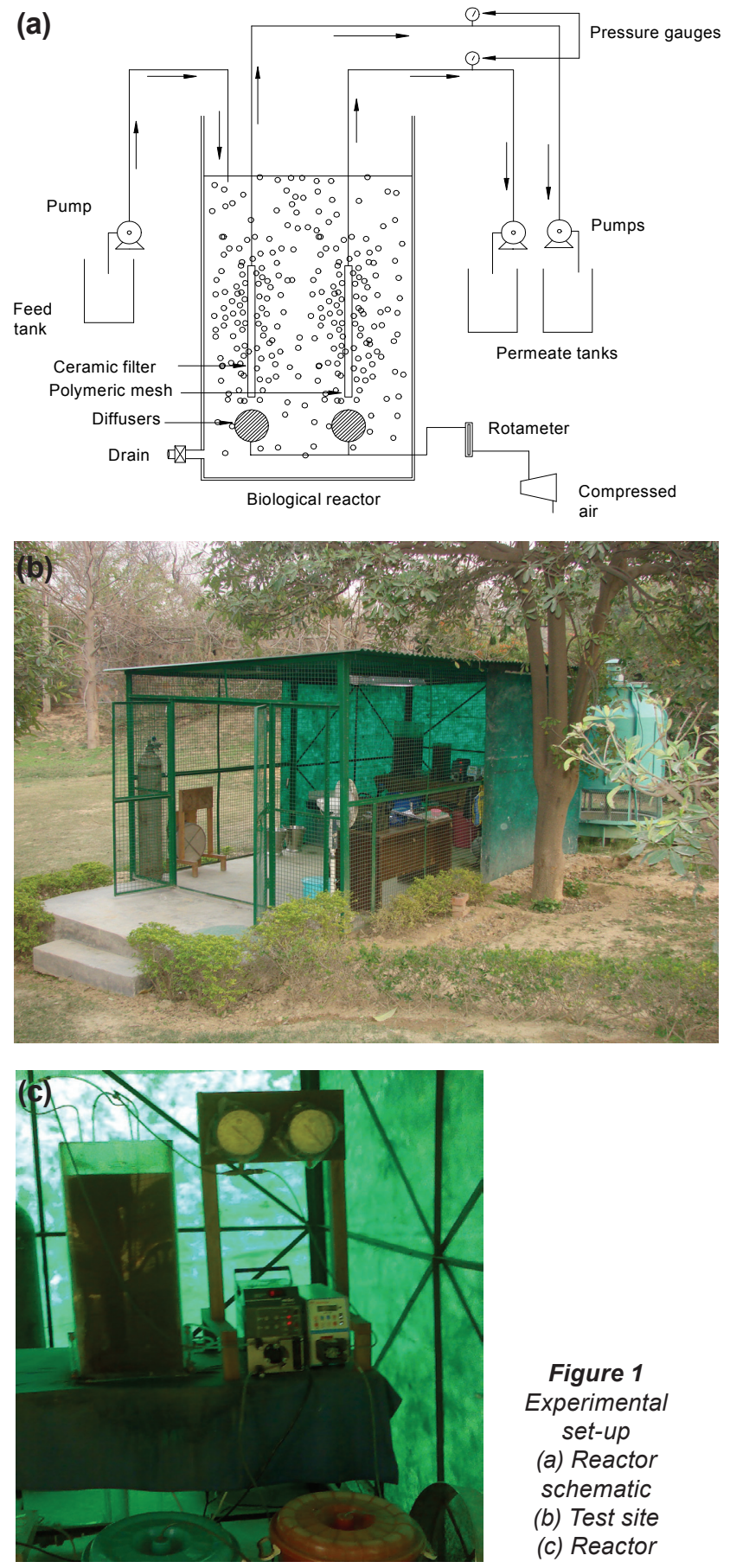

Figure 1

Experimental set-up

(a) Reactor

schematic

(b) Test site

(c) Reactor

\section{Operation and analysis}

The critical flux was determined by step-wise increase in the flux and monitoring of the corresponding TMP (Le-Clech et al., 2003). Each run started at a low constant flux, which was maintained for a fixed time. If there was no obvious increase in the TMP, the flux was stepped up to the next level by changing the suction pump speed. The procedure was repeated till a significant variation in TMP was observed. A step height of 5-10 $\ell \cdot \mathrm{m}^{-2} \mathrm{~h}^{-1}$ and step duration of around $20 \mathrm{~min}$ was used.

The MBR trials were carried out at ambient temperature for a period of 160 days. The temperature of the reactor contents, which varied between 9 and $29^{\circ} \mathrm{C}$, was not controlled. The biological reactor was inoculated with $1.2 \mathrm{~g} \cdot \ell^{-1}$ of fresh activated sludge obtained from a municipal sewage treatment plant in Delhi. The $\mathrm{pH}$ of the reactor contents was maintained around 7 by addition of $\mathrm{NaOH}$ or $\mathrm{HCl}$, as required. Filtration and regular monitoring of the system was initiated after 30 days of inoculation. Suction was intermittent $(8.5 \mathrm{~min}$ on and $1.5 \mathrm{~min}$ off over a 10 min cycle) to minimise long-term fouling. Flux and TMP were recorded twice daily and the average was reported. Data recording and sample collection were done at the same time on all working days. On weekends and holidays, feed inflow was stopped but aeration was continued. The ceramic filter was changed periodically over the test duration once the TMP went beyond the limit. The polymeric mesh was rinsed periodically with water to remove the surface deposits; this was done observing the flux decline and TMP rise.

To enable nitrogen removal without external carbon addition, batch anoxic stage was followed by aerobic stage. Over a $24 \mathrm{~h}$ cycle, the system was maintained under anoxic conditions for $3 \mathrm{~h}$ where aeration and filtration were both stopped. Dissolved oxygen (DO) levels (monitored using portable DO meter, OXI 330i/SET, Germany) were between 2.3 and $5.7 \mathrm{mg} \cdot \ell^{-1}$ during aerobic operation and 0.1 and $1.9 \mathrm{mg} \cdot \ell^{-1}$ in the anoxic stage.

Samples of feed, reactor and permeate were collected and analysed regularly for chemical oxygen demand (COD), mixed liquor suspended solids (MLSS), volatile suspended solids (VSS), $\mathrm{NH}_{4}^{+}$, and $\mathrm{PO}_{4}^{3-}$ as per standard methods (Clesceri et al., 1998).

MLSS and VSS retention by the filters were calculated as follows:

Retention $(\%)=(1-$ Permeate content $/$ Reactor content $) \times 100$

Removal of COD, $\mathrm{NH}_{4}^{+}$, and $\mathrm{PO}_{4}{ }^{3-}$ were calculated as follows:

Removal $(\%)=(1-$ Permeate content $/$ Feed content $) \times 100$

\section{Results and discussion}

The following sections report representative results obtained over 100 days of continuous operation.

\section{Critical flux}

Figure 2 shows the findings of critical flux measurement. It is evident that for the polymeric mesh, the critical flux was above the range tested. In contrast, a critical flux of around $40 \ell \cdot \mathrm{m}^{-2} \cdot \mathrm{h}^{-1}$ was observed with the ceramic filter. A flux of $14 \ell \cdot \mathrm{m}^{-2} \cdot \mathrm{h}^{-1}$ (that was well below the critical flux) was subsequently imposed upon both filters during MBR testing.

\section{MBR performance}

\section{Flux and TMP}

The flux and TMP profile is shown in Fig. 3. With the polymeric mesh, in the initial 30 days of operation, the flux was stable with minimal TMP rise. Thereafter a TMP build-up was noticed; the module was then removed and washed with tap water. Flux and TMP were restored to their original values upon washing and remained so for the next 20 days, on average. In comparison, the ceramic filter was able to maintain stable flux without significant TMP build-up for longer periods (30-40 days). Beyond a certain TMP, the filter developed small cracks which led to sudden drop in TMP. However, these 


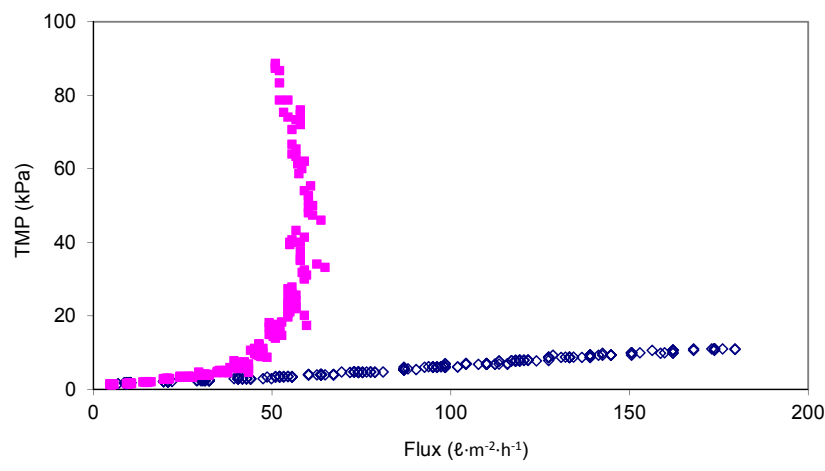

Figure 2

Critical flux of polymeric mesh (MLSS $1.05 \mathrm{~g} \cdot \ell-1)$ and ceramic filter (MLSS $1.08 \mathrm{~g} \cdot \ell-1)$

- Flux(Polymeric) घ Flux (Ceramic) $\square \operatorname{TMP}($ Polymeric) $\square \operatorname{TMP}($ Ceramic)

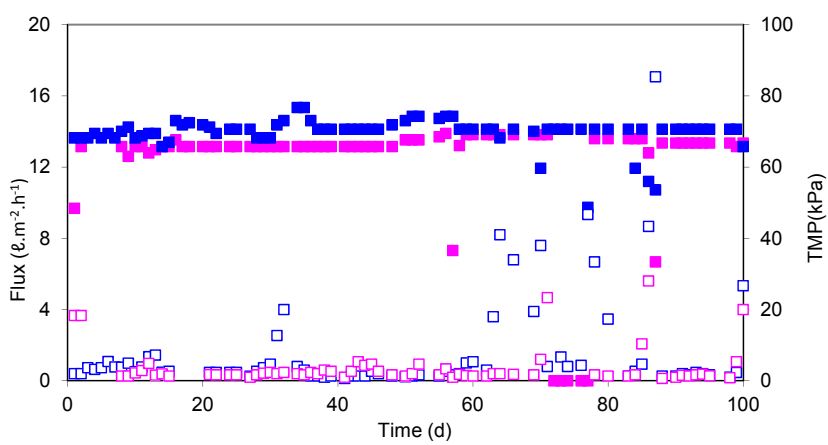

Figure 3

Flux and TMP profiles for polymeric mesh and ceramic filter

cracks were sealed in situ by deposition of the sludge and did not noticeably affect the flux or separation characteristics.

\section{Suspended solids retention}

The biomass growth was monitored in terms of MLSS and VSS content in the reactor. The suspended solids retention was high (Fig. 4), with an average retention of around $96 \%$ with both filters. The results are comparable to that obtained with synthetic wastewater (average MLSS retention of $92 \%$ with polymeric and $96 \%$ with ceramic membrane) (Tewari et al., 2010).

\section{COD, nitrogen and phosphorus removal}

Over the course of MBR operation, the average hydraulic retention time (HRT) was $20 \pm 5 \mathrm{~h}$ and the solids retention time (SRT) was $19 \pm 16$ days. The average COD removal efficiency was around $74 \%$ with a permeate COD of $55 \pm 30 \mathrm{mg} \cdot \ell^{-1}$ (polymeric mesh) and $58 \pm 32 \mathrm{mg} \cdot \ell^{-1}$ (ceramic filter) (Fig. 5). The average nitrogen removal (in terms of $\mathrm{NH}_{4}^{+}$) was estimated to be nearly $80 \%$ with the permeate $\mathrm{NH}_{4}^{+}$content of $0.17 \pm$ 0.12 (polymeric mesh) and $0.19 \pm 0.14$ (ceramic filter). The $\mathrm{PO}_{4}^{3-}$ content in the permeate was $7.72 \pm 1.90 \mathrm{mg} \cdot \ell^{-1}$ (polymeric $\mathrm{mesh}$ ) and $7.83 \pm 1.48 \mathrm{mg} \cdot \ell^{-1}$ (ceramic filter) and the average phosphorus removal (in terms of $\mathrm{PO}_{4}^{3-}$ ) was calculated to be around $48 \%$.

The overall system performance was moderate and the removal efficiencies were somewhat lower than the literaturereported values. For submerged MBRs employing nitrification

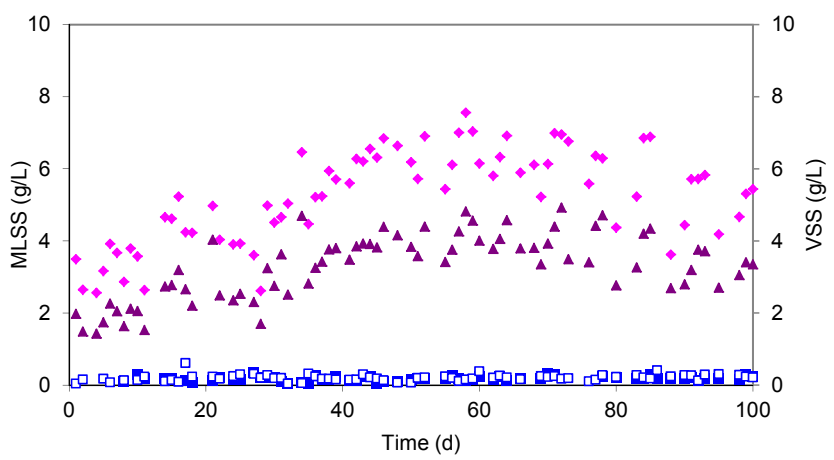

Figure 4

Suspended solids content in reactor and permeate from polymeric mesh and ceramic filter

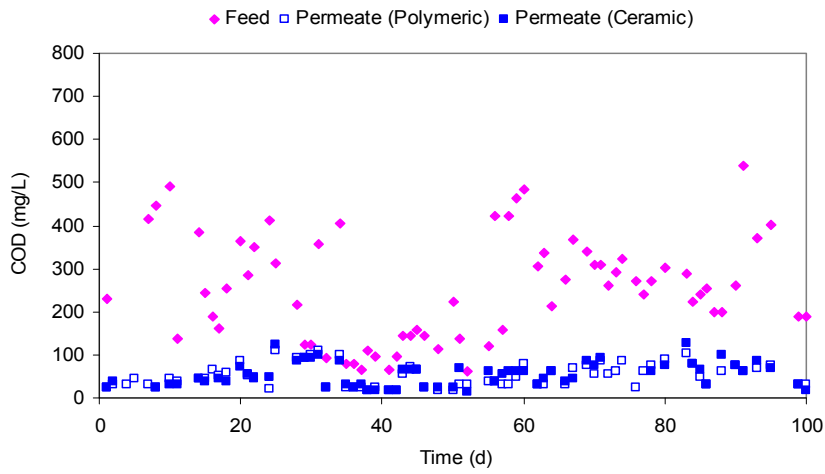

Figure 5

$C O D$ content in feed and permeate from polymeric mesh and ceramic filter

and denitrification stages, COD removal is mostly above $90 \%$; such systems typically operate at an average MLSS of $10 \mathrm{~g} \cdot \ell^{-1}$ or above. In this study, the average MLSS was around $5.8 \mathrm{~g} \cdot \ell^{-1}$ and the VSS/MLSS ratio was around 0.6. The latter is somewhat lower than the reported range of 0.7-0.9 in biological treatment (Rosenberger et al., 2002). In these tests, the HRT was relatively high compared to typical values of 6-12 h for low-strength municipal wastewater. As a result of the long HRT / low organic loading, starvation of microorganisms can occur, leading to low biomass activity. The aeration was continued on weekends and holidays in the absence of influent flow. This prevented putrefaction but would also contribute to biomass decay (Siegrist et al., 1999). Further, the reactor contents experienced variations in temperature $\left(9-29^{\circ} \mathrm{C}\right)$, influent $\mathrm{COD}\left(46-697 \mathrm{mg} \cdot \ell^{-1}\right)$ and $\mathrm{PO}_{4}^{-3}$ content $\left(6.06-53.31 \mathrm{mg} \cdot \ell^{-1}\right)$. Fluctuation in the influent characteristics affects the denitrification efficiency (Kimura et al., 2008). Thus combinations of the above factors are likely to have adversely influenced the biological degradation.

\section{Issues in operation}

The polymeric mesh displayed rapid TMP rise accompanied by a flux decline, after around 30 days of operation. The initial conditions can be restored by rinsing the module with tap water to remove the suspended solids adhering to the mesh. However, the effect is temporary and rinsing needs to be repeated every 7-20 days. Chemical cleaning with $0.1-0.5 \mathrm{~N} \mathrm{NaOH}$ to solubilise organic foulants was examined in our earlier work with 
synthetic wastewater but was not effective (Tewari et al., 2010). An optimal cleaning strategy therefore needs to be evolved for such meshes. This aspect has not received much attention even in recent works (Ren et al., 2010); however some solutions have been suggested e.g. back-flush with air combined with mechanical cleaning (Zahid and El-Shafai, 2011), membrane surface modification with coating of chitosan (Wang et al., 2010), powdered activated carbon (Ye et al., 2006), etc. It is to be noted that membranes requiring frequent cleaning would not be appropriate for decentralised systems as repeated cleaning would contribute towards higher maintenance cost.

The ceramic filters used in this work had a tendency to develop cracks if the TMP underwent a sudden increase. Thus the process design should take into account the TMP limits and develop an appropriate cleaning schedule to ensure this limit is not reached. In this work, the ceramic filter was not cleaned and was replaced once cracks developed. Replacement was done about once in 25 days. Ceramic membrane cleaning procedures in wastewater treatment have reported sequential use of alkali and acid combined with oxidative chlorine-based cleaners and detergents (e.g. Zhong et.al 2007; Rahman and Al-Malack, 2006). Thus, suitable cleaning protocols have to be evolved for the filters used in this work as well. In parallel, improvements in the module design and filter strength are also being addressed so that the next generation of filters is capable of withstanding higher TMPs.

Because of the varied occupancy of the residential complex over the test period, there was considerable variation in the volume and characteristics of the generated wastewater; overall, the wastewater strength was low (average COD 250 $\left.\mathrm{mg} \cdot \ell^{-1}\right)$. Also, the feed to the MBR was a grab sample that was collected at a fixed time every morning. Moreover, seasonal variations in temperature were experienced. The temperature of the reactor contents was in the $10-15^{\circ} \mathrm{C}$ range in the winter months of December and January. However, no observable additional decline in either COD or nutrient removal was noted during this period. Feed equalisation may be considered to avoid shock loads from diurnal variations as reported in the treatment of highly fluctuating raw sewage using a 2-chamber MBR (Abegglen et al., 2008). Further, the option of anoxic or anaerobic operation in the absence of feed inflow also needs to be examined to minimise biomass decay. The overall operation procedure in terms of the HRT, duration of anoxic and aerobic stages, etc., also requires optimisation. This work is currently underway.

\section{Conclusions}

The ash-based ceramic filter appears promising in terms of both long-term stable flux and high sludge retention in a submerged MBR. However, filter and module design needs to be improved and appropriate cleaning protocols evolved to ensure that TMP limits are not exceeded.

The MBR system design has to incorporate solutions to handle large fluctuations in influent flow and properties; in particular, effective operation in the absence of influent flow needs to be examined.

\section{Acknowledgements}

The authors gratefully acknowledge the financial support from TERI to conduct this work. The authors also thank Mr Manjul Sarkar for assistance in reactor setup, operation and monitoring and Mr BS Bisht for laboratory assistance.

\section{References}

ABEGGLEN C, OSPELT M and SIEGRIST H (2008) Biological nutrient removal in a small-scale MBR treating household wastewater. Water Res. 42 338-346.

BATRA VS and TEWARI PK (2006) A process for the preparation of inorganic membrane filters for solid liquid and solid-gas separations. Indian patent (in process).

CHANG IS, GANDER M, JEFFERSON B and JUDD SJ (2001) Low-cost membranes for use in a submerged MBR. Trans. Inst. Chem. Eng. (Part B) 79 183-188.

CHANG WK, HU AYJ, HORNG RY and TZOU WY (2007) Membrane bioreactor with nonwoven fabrics as solid-liquid separation media for wastewater treatment. Desalination 202 122-128.

CLESCERI LS, GREENBERG AE and EATON AD (1998) Standard Methods for the Examination of Water and Wastewater $\left(20^{\text {th }} \mathrm{edn}\right.$.). American Public Health Association, Washington.

JEDIDI I, SAÏDI S, KHEMAKHEM S, LARBOT A, ELLOUMIAMMAR N, FOURATI A, CHARFI A, BEN SALAH A and BEN AMAR R (2009) Elaboration of new ceramic microfiltration membranes from mineral coal fly ash applied to waste water treatment. J. Hazard. Mater. 172 152-158.

KIMURA K, NISHISAKO R, MIYOSHI T, SHIMADA R and WATANABE Y (2008) Baffled membrane bioreactor (MBR) for efficient nutrient removal from municipal wastewater. Water Res. 42 625-632.

KISO Y, JUNG Y, ICHINARI T, KITAO T, NISHIMURA K and MIN K (2000) Wastewater treatment performance of a filtration bio-reactor equipped with a mesh as a filter material. Water Res. 34 4143-4150.

LE-CLECH P, JEFFERSON B, CHANG IS and JUDD SJ (2003) Critical flux determination by the flux-step method in a submerged membrane bioreactor. J. Membr. Sci. 227 81-93.

NANDI BK, UPPALURI R and PURKAIT MK (2009) Treatment of oily waste water using low-cost ceramic membrane: Flux decline mechanism and economic feasibility. Sep. Sci. Technol. 44 2840-2869.

RAHMAN MM and AL-MALACK MH (2006) Performance of a crossflow membrane bioreactor (CF-MBR) when treating refinery wastewater. Desalination 191 16-26.

REN X, SHON HK, JANG N, LEE YG, BAE M, LEE J, CHO K and KIM IS (2010) Novel membrane bioreactor (MBR) coupled with a nonwoven fabric filter for household wastewater treatment. Water Res. 44 751-760.

ROSENBERGER S, KRUGER U, WITZIG R, MANZ W, SZEWYK U and KRAUME M (2002) Performance of a bioreactor with submerged membranes for the aerobic treatment of municipal wastewater. Water Res. 36 413-420.

SIEGRIST H, BRUNNER I, KOCH G, PHAN LC and LE VC (1999) Reduction of biomass decay rate under anoxic and anaerobic conditions. Water Sci. Technol. 39 129-137.

TEWARI PK, SINGH RK, BATRA VS and BALAKRISHNAN M (2010) Membrane bioreactor (MBR) for wastewater treatment: Filtration performance evaluation of low cost polymeric and ceramic membranes. Sep. Purif. Technol. 71 200-204.

WANG C, YANG F, MENG F, ZHANG H, XUE Y and FU G (2010) High flux and antifouling filtration membrane based on non-woven fabric with chitosan coating for membrane bioreactors. Bioresour. Technol. $1015469-5474$.

WU Y, HUANG X and ZUO W (2005) Effect of mesh pore size on performance of self-forming dynamic membrane coupled bioreactor for domestic wastewater treatment, future of urban wastewater systems - decentralization and reuse. IWA International Conference, Xi'an China, 18-20 May, 2005.

YE M, ZHANG H, WEI Q, LEI H, YANG F and ZHANG X (2006) Study on the suitable thickness of a PAC-precoated dynamic membrane coupled with a bioreactor for municipal wastewater treatment. Desalination 194 108-120.

ZAHID WM and EL-SHAFAI SA (2011) Use of cloth-media filter for membrane bioreactor treating municipal wastewater. Bioresour. Technol. 102 2193-2198.

ZHONG Z, XING W, LIU X, JIN W and XU N (2007) Fouling and regeneration of ceramic membranes used in recovering titanium silicalite-1 catalysts. J. Membr. Sci. 301 67-75. 